\title{
An approach for understanding the heredity of two quality traits (head color and tightness) in globe artichoke (Cynara scolymus L.)
}

\author{
Vanina Pamela Cravero ${ }^{1}$, Liliana Amelia Picardi ${ }^{2}$ and Enrique Luis Cointry ${ }^{2}$ \\ ${ }^{1}$ Consejo Nacional de Investigaciones Científicas y Técnicas, Buenos Aires, Argentina. \\ ${ }^{2}$ Universidad Nacional de Rosario, Facultad de Ciencias Agrarias, Consejo de Investigaciones UNR, \\ Cátedra de Genética, Santa Fe, Argentina.
}

\begin{abstract}
The inheritance of head color and tightness in globe artichoke was studied utilizing crosses between inbreed lines and between clones and self-pollinated clones from different genetic origins. These genetic materials were sowed in a completely randomized design with 20 plants per plot and genotype. Globe artichoke heads were classified into three colors (purple-green, purple and green) and three head tightness types (compact, fairly compact and soft) and the segregating ratios for these traits tested in each offspring using the chi-square test. Crosses between green and purple inbreed lines produced only purple-green heads but $F_{2}$ generation segregated at a purple-green:purple:green ratio of 9:3:4. The self-pollinated compact head clones produced a compact head:fairly compact head:soft head ratio of 12:3:1. The remaining crosses between lines and among clones and backcrosses verified these ratios. These results suggest that two loci with a simple recessive epistasis are involved in the inheritance of head color and that two loci with simple dominant epistasis are involved in the expression of the different head tightness types. The inheritance models proposed here could be helpful in predicting the appearance of artichoke heads if breeders need to obtain hybrid seeds for a desirable phenotype.
\end{abstract}

Key words: globe artichoke, heredity, inbreed lines, clones, epistasis.

Received: August 6, 2004; Accepted: April 12, 2005.

\section{Introduction}

Argentina is the fourth largest producer of globe artichokes (Cynara scolymus L.), with about 2000 hectares under cultivation at an annual yield of about $8500 \mathrm{~kg}$ of artichokes per hectare and a mean income of U\$S 6375 per hectare (García et al., 2000). Tightness and head color are important traits that define the quality of a globe artichoke cultivar because consumers in different countries and regions are very sensitive to such traits (Aubert, 1976; Macua, 1996). Differences in head color in this species are depended on the intensity and location of anthocyanin pigments, with cultivars (cv) such as Camus de Bretagne completely green (lacking in anthocyanins) whereas all the bracts of cv Reri 1-1-18 are purple while cultivars such as Nato show a uneven purple color in some areas of the bracts. These cultivars are a sample of genotypes showing the high phenotypic variability in the globe artichoke cultivars for head color.

Corresponding author: Enrique Luis Cointry. Universidad Nacional de Rosario, CC 14 (S2125ZAA) Santa Fe, Argentina. E-mail: ecointry@fcagr.unr.edu.ar.
In general, a useful tool for improving cultivar quality traits in a breeding program is to understand the rules governing the inheritance of traits. Several papers (Foury, 1969; Sarno, 1973; Foury and Aubert, 1977) on inheritance in artichokes have proposed monogenic inheritance where purple head color is governed by dominant genes and green color by recessive genes. The appearance of artichoke heads is also related to head tightness which is another desirable trait, not only esthetically but also for reasons related to harvesting and packing-shed considerations. Head tightness is related to bract shape and position on the head and varies among cultivars from soft to compact with soft head being the least commercially desirable type, although there is no information on the inheritance of this trait.

In this trial, we performed several crosses between inbreed lines and between clones and self-pollinated clones from different genetic origins to study the heredity of head color and tightness, two traits that define quality in globe artichoke cultivars. Segregating generations of these crosses were analyzed and a model based on these results is proposed to explain the genetics base of artichoke color and tightness. 


\section{Material and Methods}

The experiments were carried out at the experimental station of Rosario National University, Zavalla, Santa Fe, Argentina ( $\left.33^{\circ} 01^{\prime} \mathrm{S}, 60^{\circ} 53^{\prime} \mathrm{W}\right)$.

\section{Genetic material}

Seeds from genetically different artichokes representing the different types of artichoke head color and tightness were obtained from a local globe artichoke breeding program and from several regional cultivars. At least 16 seeds of each cultivar were sown under normal conditions for artichoke cultivation. Inbred lines were crossed (MS 8380, Reri 1-1-18, Cada 233-29 and Riga 5-12), clones were self-pollinated (II 35-4, II 9-5, 134, 60-3, I 34-4, 107, 102 , 151 and 128) and crosses between clones were also made (II 9-12 x II 9-17, Ñato x Salanquet, Nato x Cacique, 189 x Cacique and 189 x Camus de Bretagne). Each plant was considered as an experimental unit with head color and tightness being recorded for the first harvested head.

Three head colors occurred, a) green without anthocyanin pigments; b) purple due to the presence of anthocyanin pigments and c) purple-green because of uneven anthocyanin distribution within the bracts. Head tightness was determined by hand pressure (Dellacecca et al., 1976) and classified as follows: 1) compact head, with un- modified imbricate bracts showing no separation when squeezed by hand 2) fairly compact head, with less imbricate bracts as compared to the compact head plants and showing sight separation of the bracts when squeezed; and 3) soft head, with divergent bracts showing strong separation when squeezed. See Table 1 for the head colors and Table 2 for head tightness of the different genotypes.

The segregated genetic ratios for head color and tightness were tested in each offspring using the chi-square $\left(\mathrm{X}^{2}\right)$ test (Sokal and Rohlf, 1995) according to the hypothesis of inheritance proposed for each trait.

\section{Results and Discussion}

\section{Head color}

Crosses between green and purple lines produced single hybrid $\mathrm{F}_{1}$ plants with $100 \%$ purple-green heads. The $\mathrm{F}_{2}$ generations showed a head color ratio of 9:3:4 purple-green:purple:green, similar results being observed when the double hybrid between both single hybrids was performed. One backcross was also performed between the purple-green $F_{1}$ (MS 8380 x Reri 1-1-18) and the purple line Reri 1-1-18, this cross producing an offspring with a purple-green: purple ratio of 3:1 (Table 1).

Table 1 - Globe artichoke head color. Observed offspring segregation and the putative genotypes of parental and offspring generations for purple-green $(\mathrm{PG})$, purple $(\mathrm{P})$ and green $(\mathrm{G})$ heads.

\begin{tabular}{|c|c|c|c|c|c|c|c|}
\hline \multirow[t]{2}{*}{ Genotipes } & \multicolumn{5}{|c|}{ Offspring observed } & \multicolumn{2}{|c|}{ Putative genotype } \\
\hline & PG & $\mathrm{P}$ & G & Ratio & $X^{2}$ & Parental & Offspring \\
\hline \multicolumn{8}{|l|}{ Single hybrid } \\
\hline MS 8380 (G) X Reri 1-1-18 (P) & 23 & & & $1: 0: 0$ & $0.00^{\mathrm{ns}}$ & ppUU X PPuu & $\mathrm{PpUu}$ \\
\hline Cada 233-29 (P) X Riga 5-12 (G) & 25 & & & $1: 0: 0$ & $0.00^{\mathrm{ns}}$ & PPuu X ppUU & $\mathrm{PpUu}$ \\
\hline \multicolumn{8}{|l|}{$\mathrm{F}_{2}$ generation } \\
\hline (Cada 233-29 X Riga 5-12) (PG) @ & 26 & 7 & 14 & $9: 3: 4$ & $0.8^{\mathrm{ns}}$ & $\mathrm{PpUu}$ & P-U-, P-uu, pp-- \\
\hline (MS 8380 X Reri 1-1-18) (PG)@ & 30 & 8 & 13 & $9: 3: 4$ & $0.3^{\mathrm{ns}}$ & PpUu & P-U-, P-uu, pp-- \\
\hline $\begin{array}{l}\text { Double hybrid } \\
\text { (MS } 8380 \text { X Reri 1-1-18) (PG) X } \\
\text { (Cada 233-29 X Riga 5-12) (PG) }\end{array}$ & 18 & 6 & 6 & $9: 3: 4$ & $0.4^{\mathrm{ns}}$ & PpUu X PpUu & P-U-, P-uu, ppU-, ppuu \\
\hline $\begin{array}{l}\text { Backcross } \\
(\text { MS } 8380 \text { X Reri 1-1-18) (PG) X } \\
\text { Reri 1-1-18 (P) }\end{array}$ & 10 & 6 & 0 & $1: 1: 0$ & $1.0^{\mathrm{ns}}$ & PpUu X PPuu & P-U-, P-uu \\
\hline \multicolumn{8}{|l|}{ Clones - self-pollinated } \\
\hline II-35-4 (G)@ & 0 & 0 & 30 & $0: 0: 1$ & $0.00^{\mathrm{ns}}$ & pp-- & pp-- \\
\hline II-9-5 (P)@ & 0 & 32 & 0 & $0: 1: 0$ & $0.00^{\mathrm{ns}}$ & PPuu & PPuu \\
\hline $134(\mathrm{P}) @$ & 0 & 24 & 6 & $0: 3: 1$ & $0.4^{\mathrm{ns}}$ & Ppuu & P-uu, ppuu \\
\hline 60-3 (PG)@ & 14 & 4 & 6 & $9: 3: 4$ & $0.08^{\text {ns }}$ & $\mathrm{PpUu}$ & P-U-, P-uu, pp-- \\
\hline I-34-4 (PG)@ & 18 & 9 & 0 & $3: 1: 0$ & $1.0^{\mathrm{ns}}$ & PPUu & PPU-, PPuu \\
\hline 107 (PG)@. & 27 & 0 & 13 & $3: 0: 1$ & $1.2^{\mathrm{ns}}$ & PpUU & P-UU, ppUU \\
\hline \multicolumn{8}{|l|}{ Clones - crosses } \\
\hline II-9-12 (PG) X II-9-17 (G) & 15 & 0 & 18 & $1: 0: 1$ & $0.3^{\mathrm{ns}}$ & PpUU X pp-- & PpU-, pp-- \\
\hline
\end{tabular}

$\mathrm{X}^{2}=$ chi-square test $(\mathrm{p}<0.05)$.

ns $=$ not significant. 
Self-pollinated green clones produced only green head offspring but purple head clones produced two different sets of offspring when self-pollinated depending on the genotype of the parental plant, the II-9-5 genotype producing $100 \%$ purple head offspring while the 134 genotype produced offspring at a purple:green ratio of $3: 1$. These results confirm those reported by Pochard et al. (1969) and Foury (1969). When the purple-green clones were self-pollinated the genotypes gave different segregation rates in the offspring, the 60-3 genotype showing a purple-green:purple:green ratio of 9:3:4 but the I-34-4 genotype gave a purple-green:purple ratio of 3:1 while the 107 genotypes resulted in a purple-green:green ratio of 3:1 (Table 1). The remaining crosses between purple-green and green head clones gave equal numbers of purple-green and green head offspring.

These results suggested that one locus with two alleles $(\mathrm{P}, \mathrm{p})$ could be involved in the determination of the artichoke head color. Based on the observed segregation rate shown in Table 1, one of these alleles could be dominant for producing anthocyanins in all bracts of the head but when this dominant allele is absent the bracts have no pigmentation and are totally green. An independent second locus with two alleles $(\mathrm{U}, \mathrm{u})$ could explain purple-green heads occurrence, the dominant allele of this second locus being responsible for producing an uneven pattern of anthocyanins in the bracts depending on the genetic constitution of the first locus. Our data suggest that these two independent loci, each one with complete dominance, produces a simple recessive epistatic interaction which defines the three different head colors, this hypothesis being supported by the fact that non-significant chi-squared values were found when the simple recessive epistatic segregation hypothesis was tested for the different offspring (Table 1). This hypothesis is also supported by Sarno (1973) who selfpollinated purple-green head genotypes and found purplegreen and green heads in the $S_{1}$ offspring, suggesting that purple-green is dominant over green. On the other hand, however, Foury and Aubert (1977) proposed that many inhibitor genes could interrupt anthocyanin synthesis at different stages of head tissues development.

We propose that inheritance of head color in globe artichoke is governed by the following alleles: $P$, allowing anthocyanin production resulting in purple bracts; $p p$, inhibiting anthocyanin production resulting in green bracts; $U$ : producing uneven distribution of the anthocyanin pigment(s) coded by the $P$ allele and $u u$ : not producing an uneven distribution of pigment in the presence of the $P$ allele

It is possible that other modifier genes or multiple alleles could be involved in the expression of globe artichoke head color but, nevertheless, our proposed inheritance model is still a useful approach which could be adopted by artichoke breeders to enhance cultivar color quality.

\section{Head tightness}

Based on the classification of Dellacecca et al. (1976) we found that crosses between soft and fairly compact head lines produced a single hybrid $\mathrm{F}_{1}$ offspring which all had fairly compact heads but when these single hybrids were crossed with a compact head single hybrid to produce a double hybrid the result offspring were produced at a compact:fairly compact:soft head ratio of 4:3:1 (Table 2).

It is common to find tight heads in commercial cultivars but when these are self-pollinated offspring with divergent bracts and soft head can occur. In our trials with the $\mathrm{S}_{1}$ and $\mathrm{F}_{1}$ generations obtained by self-pollination and crossing clones different results were obtained, with the self-pollinated compact head genotypes producing a high proportion of offspring with the same degree of tightness as the parental genotypes and a low proportion of soft head plants. Some of the self-pollinated compact head clones (Cacique, II 35-4, 102, 134 and 151) produced offspring at a compact: fairly compact: soft head segregation ratio of 12:3:1, while clones 128 and II-9-5 produced off spring at a compact:fairly compact head ratio of $3: 1$. Similar results were found when crosses between compact headed clones were analyzed. All of the crosses between fairly compact head clones and compact head clones gave a compact:fairly compact:soft head ratio of $2: 1: 1$ and when soft headed clones were self-pollinated all the offspring shown soft head.

Dellacecca and Marzi (1976) suggested a more defined relationship between head form and tightness, compact heads being globular or sub-globular because the arrangement of bracts contribute to tightness. Also, according to Foury (1969), low bract number and a large internal bract concavity provoke head deformation during handling which results lengthwise bract breakage.

As was the case for the head color trait, the proportion offspring produced by the different crosses and by self-pollination allowed us to postulate two loci responsible for the determination of head tightness in globe artichoke and we feel that despite the complexity of this trait a simple dominant epistasis model could be the best approach to understanding the inheritance of this trait. Our proposed model consists of two independent loci: $C$, compact head; $c c$, soft head; $H$, increased head tightness in the presence of the cc genotype; and $h h$, no increased head tightness in the presence of the cc genotype.

According to our model, the $C$ and $H$ genes are duplicated loci but with different levels of penetrancy such that when the dominant $C$ allele is present in the first locus a compact head is the final phenotype independent of the genetic constitution of the second locus, but when the $H$ allele is present tightness is increased in the absence of the $C$ allele. Again, in these trials non-significant chi-square values were found when the hypothesis of simple dominant epistatic segregation was tested for in the different offspring (Table 2). 
Table 2 - Globe artichoke head tightness. Observed offspring segregation and the putative genotypes of parental and offspring generations for compact (C), fairly compact (FC) and soft (S) heads.

\begin{tabular}{|c|c|c|c|c|c|c|c|}
\hline \multirow[t]{2}{*}{ Genotipes } & \multicolumn{5}{|c|}{ Offspring observed } & \multicolumn{2}{|c|}{ Putative genotypes } \\
\hline & $\mathrm{C}$ & $\mathrm{FC}$ & S & Ratio & $X^{2}$ & Parental & Offspring \\
\hline \multicolumn{8}{|l|}{ Single hybrid } \\
\hline MS 8380 X Reri 1-1-18 (S x FC) & 0 & 30 & 0 & $0: 1: 0$ & $0.00^{\mathrm{ns}}$ & $\operatorname{cchh} \times \mathrm{ccHH}$ & $\mathrm{ccHh}$ \\
\hline $\begin{array}{l}\text { Double hybrid } \\
\text { (MS } 8380 \text { X Reri 1-1-18) X (Cada } \\
\text { 233-29 X Riga 5-12) (FC X C) }\end{array}$ & 8 & 6 & 2 & $4: 3: 1$ & $0.00^{\mathrm{ns}}$ & $\mathrm{ccHh} \times \mathrm{CcHh}$ & Cc--, ccH-, cchh \\
\hline \multicolumn{8}{|l|}{ Clones - self-pollinated } \\
\hline Cacique@(C) & 15 & 3 & 3 & $12: 3: 1$ & $2.4^{\mathrm{ns}}$ & $\mathrm{CcHh}$ & C-H-, C-hh, ccH-, cchh \\
\hline II 35-4@(C) & 27 & 7 & 2 & $12: 3: 1$ & $0.04^{\mathrm{ns}}$ & $\mathrm{CcHh}$ & C-H-, C-hh, ccH-, cchh \\
\hline $102 @(\mathrm{C})$ & 13 & 3 & 1 & $12: 3: 1$ & $0.02^{\mathrm{ns}}$ & $\mathrm{CcHh}$ & C-H-, C-hh, ccH-, cchh \\
\hline $134 @(\mathrm{C})$ & 34 & 12 & 1 & $12: 3: 1$ & $2.5^{\mathrm{ns}}$ & $\mathrm{CcHh}$ & C-H-, C-hh, ccH-, cchh \\
\hline $151 @(\mathrm{C})$ & 14 & 2 & 2 & $12: 3: 1$ & $1.0^{\mathrm{ns}}$ & $\mathrm{CcHh}$ & C-H-, C-hh, ccH-, cchh \\
\hline $128 @(\mathrm{C})$ & 21 & 10 & 0 & $3: 1: 0$ & $0.9^{\mathrm{ns}}$ & $\mathrm{CcHH}$ & $\mathrm{C}-\mathrm{HH}, \mathrm{ccHH}$ \\
\hline II 9-5@(C) & 37 & 9 & 0 & $3: 1: 0$ & $0.7^{\mathrm{ns}}$ & $\mathrm{CcHH}$ & $\mathrm{C}-\mathrm{HH}, \mathrm{ccHH}$ \\
\hline $107 @(\mathrm{~S})$ & 0 & 0 & 29 & $0: 0: 1$ & $0.00^{\mathrm{ns}}$ & $\operatorname{cchh}$ & $\operatorname{cchh}$ \\
\hline \multicolumn{8}{|l|}{ Clones - crosses } \\
\hline Ñato x Salanquet (C X C) & 7 & 2 & 0 & $3: 1: 0$ & $0.2^{\mathrm{ns}}$ & $\mathrm{CcHH} \times \mathrm{Cchh}$ & $\mathrm{C}-\mathrm{Hh}, \mathrm{ccHh}$ \\
\hline Nato X Cacique (C X C) & 10 & 6 & 0 & $3: 1: 0$ & $1.3^{\mathrm{ns}}$ & $\mathrm{CcHH} \times \mathrm{Cchh}$ & $\mathrm{C}-\mathrm{Hh}, \mathrm{ccHh}$ \\
\hline 189 X Cacique (FC X C) & 10 & 6 & 5 & $2: 1: 1$ & $0.1^{\mathrm{ns}}$ & $\mathrm{ccHh} \times \mathrm{Cchh}$ & $\mathrm{Cc}-\mathrm{h}, \mathrm{ccHh}, \mathrm{cchh}$ \\
\hline 189 X Camus de Bretagne(FC X C) & 18 & 9 & 7 & $2: 1: 1$ & $0.4^{\mathrm{ns}}$ & $\mathrm{ccHh} \times \mathrm{Cchh}$ & $\mathrm{Cc}-\mathrm{h}, \mathrm{ccHh}, \mathrm{cchh}$ \\
\hline
\end{tabular}

$\mathrm{X}^{2}=$ chi-squar test $(\mathrm{p}<0.05)$.

ns $=$ not significant.

Epistatic interaction has frequently been cited as a common genetic mechanism in the inheritance of several important globe artichoke traits. De Pace et al. (1973), analyzing crosses between the cultivars Spinoso Sardo, Castellamare and Violet de Provence have suggested that the thornless bract trait is governed by two loci with a double epistatic interaction fitting the 9:7 ratio for thorn absence:thorn presence.

Globe artichoke color and head tightness are complex traits in which many metabolic pathways may be involved so it may be necessary to evaluate other artichoke genotypes to validate our model, but even so the research reported in this paper can help to predict the performance of different artichoke crosses and thus obtain hybrid seeds with desirable phenotypes and as such could be a valuable tool for artichoke breeders.

\section{References}

Aubert S (1976) Influence de la couleur des aliments et boissons sur acceptabilité: Quelques exemples. Cah Nutr Diétét 11:15-30.

Dellacecca V and Marzi V (1976) Influenza della densitá colturale e della scarducciatura sulla produzione e sulle caratteritiche qualitative dei capolini di carciofo. Atti $2^{\circ}$ Congresso Internazionale di Studi sul Carciofo: 427-466, Bari, Italy.

Dellacecca V, Magnifico V, Marzi V, Porceddu E and Scarascia Mugnozza GT (1976) Description on artichoke varieties cul- tivated in the world. Nuovi Studi sul Carciofo. Atti $2^{\circ}$ Congresso Internazionale di studi sul Carciofo: 199-316, Bari, Italy.

De Pace C, Porceddu E and Pacucci G (1973) Ulteriori resultati di una serie di incroci diallelici nel carciofo. Atti Congresso Internazionale di Studi sul Carciofo: 410-432, Bari, Italy.

Foury C (1969) Étude de la biologie florale de l'artichaut (Cynara scolymus $\mathrm{L}$ ). Application à la sélection. $2^{\circ}$ partie: Étude des descendances obtenes en fécondation controlée. Ann Amélior Plants 19:23-50.

Foury C and Aubert S (1977) Observations prèliminaires sur la présence et la répartition de pigments anthocyaniques dans un mutant d'artichaut (Cynara scolymus L.) à fleur blanches. Ann Amélior Plantes 27:603-612.

García SM, Cointry E, López Anido F, Cravero V and Firpo I (2000) Artichoke situation in Argentina. Proc. of IV International Congress on Artichoke: 29, Bari, Italy.

Macua JI (1996) Colección de variedades de alcachofa. $1^{\circ}$ Jornadas Técnicas de Alcachofa: 151-161, Tudela, Navarra, España.

Pochard E, Foury C and Chambonet D (1969) Il miglioramento genetico del carciofo. Atti $1^{\circ}$ Congresso Internazionale sul Carciofo: 117-155, Bari, Italy.

Sarno R (1973) Ricerche sul miglioramento genetico del carciofo (Cynara scolymus L.). Atti $2^{\circ}$ Congresso Internazionale di Studi sul Carciofo: 765-786, Bari, Italy.

Sokal RR and Rohlf FJ (1995) Biometry: the principles and practice of statistics in biological research. 3rd edition. W.H. Freeman and Co., New York, 887 pp. 